\title{
A STUDY OF HYPERBARIC BUPIVACAINE VERSUS ISOBARIC ROPIVACAINE FOR ELECTIVE CAESAREAN DELIVERIES
}

\author{
Radha Ramana Murthy Konda1, Laxmi Narayana Anpuram², Kousalya Chakravarthy3
}

1 Professor, Department of Anaesthesia, Niloufer Hospital, Osmania Medical College, Hyderabad.

${ }^{2}$ Assistant Professor, Department of Anaesthesia, Niloufer Hospital, Osmania Medical College, Hyderabad.

${ }^{3}$ Assistant Professor, Department of Anaesthesia, Niloufer Hospital, Osmania Medical College, Hyderabad.

\section{ABSTRACT}

\section{OBJECTIVE}

Is to compare the anaesthetic effects of intrathecal administration of hyperbaric Bupivacaine 10 mg with isobaric Ropivacaine $15 \mathrm{mg}$ for elective caesarean delivery.

\section{METHOD}

100 parturients of ASA 1 and II posted for elective caesarean delivery were randomly divided into 2 groups of 50 each: Group A received intrathecal 0.5\% Hyperbaric Bupivacaine $10 \mathrm{mg}$ and Group B received intrathecal 0.75\% isobaric Ropivacaine $15 \mathrm{mg}$. Time of onset and regression of sensory and motor blocks, haemodynamics, time of first complaint of pain, neonatal APGAR and side-effects were evaluated.

\section{RESULTS}

Ropivacaine group has significantly slower onset of sensory analgesia at T6 $(4.45 \pm 0.03$ in Ropivacaine group as against $2.38 \pm 0.36$ in Bupivacaine group, $p<0.05)$, slower onset of Grade 3 motor block $(6.46 \pm 2.48$ in Ropivacaine group, $3.06 \pm 0.9$ in Bupivacaine group $\mathrm{p}<0.05)$ and shorter duration of motor block $(102.50 \pm 11.09$ in Ropivacaine group as against $120.30 \pm 11.10$ in Bupivacaine group $\mathrm{p}<0.05$ ). Faster regression of the block to L1 and S2 was noticed in Ropivacaine group. (Regression to L1 $122.6 \pm 20.5$ in Ropivacaine and $144.10 \pm 28.19$ in Bupivacaine group, $p<0.05$; Complete sensory regression to $S_{1} 150.0 \pm 14.8$ in Ropivacaine and 169.6 \pm 20.4 in Bupivacaine group; $p<0.05$ ). Time to first complaint of pain was comparable in both the groups (168.9 \pm 26.0 in Ropivacaine and $170.2 \pm 25.5$ in Bupivacaine group $p>0.05$ ). There was no difference in the haemodynamics and neonatal APGAR. Neither of the groups had any significant intraoperative or postoperative complications.

\section{CONCLUSION}

Intrathecal Isobaric Ropivacaine $15 \mathrm{mg}$ provides effective spinal anaesthesia for caesarean delivery. It has slower onset, shorter motor block, early sensory regression and similar postoperative analgesia and APGAR scores as compared to $10 \mathrm{mg}$ of $0.5 \%$ hyperbaric bupivacaine. The shorter duration of motor block can facilitate early ambulation and makes Ropivacaine a good alternative for elective caesarean deliveries.

\section{KEYWORDS}

Ropivacaine, Bupivacaine, Anaesthesia, Caesarean Deliveries.

HOW TO CITE THIS ARTICLE: Konda RRM, Anpuram LN, Chakravarthy K. A study of hyperbaric bupivacaine versus isobaric ropivacaine for elective caesarean deliveries. J. Evolution Med. Dent. Sci. 2016;5(38):2345-2348, DOI: 10.14260/jemds/2016/544

\section{INTRODUCTION}

Ropivacaine is a long-acting amide local anaesthetic. Ropivacaine is less lipophilic than Bupivacaine resulting in a relatively reduced motor blockade, decreased potential for central nervous system and cardiotoxicity. The studies on Minimum Local Anaesthetic Concentration (MLAC) have shown that Ropivacaine has similar potency to Bupivacaine at higher doses as used in surgical anaesthesia. ${ }^{1}$ When used for caesarean section, the time of onset of analgesia with intrathecal dosage of Ropivacaine $12 \mathrm{mg}$, Levobupivacaine 8 $\mathrm{mg}$ or Bupivacaine $8 \mathrm{mg}$ was similar. ${ }^{2}$ But Ropivacaine and Levobupivacaine were associated with shorter time to recovery from sensory and motor block as compared to Bupivacaine. ${ }^{2}$

Financial or Other, Competing Interest: None.

Submission 28-03-2016, Peer Review 23-04-2016,

Acceptance 28-04-2016, Published 12-05-2016.

Corresponding Author:

Dr. Radha Ramana Murthy Konda,

E-64-Madhuranagar,

Hyderabad-500038.

E-mail: doctorradhak@yahoo.com

DOI: $10.14260 /$ jemds $/ 2016 / 544$
In the present study, we evaluated the anaesthetic effects of intrathecal Ropivacaine $15 \mathrm{mg}$ with intrathecal Bupivacaine $10 \mathrm{mg}$ in the patients posted for elective caesarean deliveries.

\section{MATERIAL AND METHODS}

A randomized prospective study was conducted at Niloufer Hospital for women and children, Osmania Medical College, Hyderabad. The study population included 100 parturients posted for elective caesarean delivery. Pregnant women of ASA 1 and II in the age group of 20-35 years (Teenage pregnancies and Advanced Maternal Age excluded) with uncomplicated pregnancies undergoing elective caesarean section were enrolled in the study. Patients with ASA grade $\geq 3$, known contraindications to $\mathrm{SAB}$, those with associated comorbidities and foetal complications were excluded from the study. The study population was randomly divided into 2 groups of 50 each: Group A received intrathecal $0.5 \%$ Hyperbaric Bupivacaine $10 \mathrm{mg}$ and Group B received intrathecal $0.75 \%$ isobaric Ropivacaine $15 \mathrm{mg}$.

All the patients received acid aspiration prophylaxis with Ranitidine $150 \mathrm{mg}$ and Metoclopramide $10 \mathrm{mg}$ orally the night before and on the morning of surgery. Once the patient 
is shifted into the operating room, baseline measurements noted and intravenous access secured. Cohydration with Lactated Ringer's solution was administered in all the patients. Subarachnoid block was performed in right lateral position as per the protocol. After the subarachnoid block, the patients were placed supine and left lateral tilt maintained with a wedge under the right hip. Oxygen was administered via Hudson's mask with a flow rate of $4 \mathrm{~L} / \mathrm{min}$. Blood pressure was monitored with NIBP cuff every 3 minutes till the completion of surgery and every $15 \mathrm{~min}$ in the postoperative period. Heart rate and rhythm were monitored with 3 lead ECG and $\mathrm{SPO}_{2}$ was monitored with pulse oximeter continuously. Hypotension was defined as $20 \%$ decrease in blood pressure from baseline values and was treated with incremental intravenous boluses of ephedrine $6 \mathrm{mg}$. Bradycardia was defined as heart rate less than 60 beats per minute and was treated with intravenous atropine $0.5 \mathrm{mg}$.

Time of onset of adequate sensory block was determined by noting the loss of discrimination to pinprick. Motor block was assessed by Modified Bromage scale. Sensory block was assessed every 2 min from 6 to 20 min and then every $10 \mathrm{~min}$ until recovery to T12. Motor block was performed at baseline, then 10, 15 and $20 \mathrm{~min}$ after intrathecal injection and as soon as possible at the end of surgery. After surgery it was performed every $15 \mathrm{~min}$. The time taken for the onset of complete motor block was noted. The regression of sensory block was assessed in the postoperative period. All the patients received postoperative analgesia with Injection Diclofenac $75 \mathrm{mg} 12^{\text {th }}$ hourly and IV Paracetamol $1 \mathrm{gm} 6^{\text {th }}$ hourly. The total duration of analgesia and request for rescue analgesia were noted. IV Tramadol 50 mg was planned to be used as rescue analgesic. APGAR score at 1 and 5 min was noted. Any postoperative side-effects like nausea and vomiting, post-dural puncture headache and neurological complications were noted.

\section{STATISTICAL ANALYSIS}

Student ' $\mathrm{t}$ ' test, Chi-square/Fisher Exact test has been used to find the significance of study parameters. $\mathrm{P}$ value $<0.05$ is taken as significant.

\section{OBSERVATIONS AND RESULTS}

All patients posted for caesarean section were in the age group between 20 and 35 years. The mean age in Group A was 22.40 \pm 3.63 years and in Group B it was 23.12 \pm 3.78 years. The difference in the mean age was not statistically significant $(p>0.05)$. The two groups were more or less homogenous. The mean weight for Group A was 55.80 \pm 5.33 kgs and Group B was 56.02 \pm 5.20 kgs. The difference in the mean weight was not statistically significant $(p>0.05)$. Similarly, the heights between the two groups were comparable. The mean height for Group A was $155.70 \pm 2.74$ cms and Group B was $155.60 \pm 2.83 \mathrm{cms}$. The difference in the mean height was not statistically significant.

\begin{tabular}{|c|c|c|c|c|}
\hline $\begin{array}{r}\text { Sl. } \\
\text { No. }\end{array}$ & $\begin{array}{c}\text { Parameter } \\
\text { (Mean) }\end{array}$ & Group A & Group B & $\begin{array}{c}\text { Statistical } \\
\text { Significance }\end{array}$ \\
\hline 1 & Age & $22.40+3.63$ & $23.12+3.78$ & $(\mathrm{p}>0.05) \mathrm{NS}$ \\
\hline 2 & Weight & $55.80 \pm 5.33$ & $56.02 \pm 5.20$ & $(\mathrm{p}>0.05) \mathrm{NS}$ \\
\hline 3 & Height & $155.70 \pm 2.74$ & $155.60 \pm 2.83$ & $(\mathrm{p}>0.05) \mathrm{NS}$ \\
\hline \multicolumn{4}{|c|}{ Table 1: Demographic Features } \\
\hline
\end{tabular}

\section{PROCEDURAL EVENTS}

\section{Duration of Surgery}

The duration of surgery was comparable in both the groups. The mean duration of surgery in Group A was $60.26 \pm 8.25$ and Group B was $61.06 \pm 9.00$. The mean was not statistically significant with $\mathrm{p}>0.05$ (Table 2).

\begin{tabular}{|c|c|c|c|}
\hline \multirow{2}{*}{$\begin{array}{c}\text { Duration of } \\
\text { Surgery in } \\
\text { Minutes }\end{array}$} & Group I & Group II & \multirow[b]{2}{*}{$\begin{array}{c}\text { Statistical } \\
\text { Significance }\end{array}$} \\
\hline & $\begin{array}{c}\text { No. of } \\
\text { Patients (\%) }\end{array}$ & $\begin{array}{c}\text { No. of } \\
\text { Patients (\%) }\end{array}$ & \\
\hline $60-90$ & $32(64 \%)$ & $33(66 \%)$ & \\
\hline $90-120$ & $18(36 \%)$ & $17(34 \%)$ & \\
\hline Mean & $60.26 \pm 8.25$ & $61.06 \pm 9.00$ & $p>0.05 \mathrm{NS}$ \\
\hline \multicolumn{4}{|c|}{ Table 2: Duration of Surgery in Minutes } \\
\hline
\end{tabular}

\section{Time of Onset and Level of Sensory Analgesia}

The time of onset sensory analgesia was noted by pinprick as soon as the patient is turned supine and a wedge kept under the right hip. In Group A, 56\% (28 patients) of patients had analgesia up to T 6 between 2 and 3 mins. The mean time taken for sensory analgesia at T6 in Group A was $2.38 \pm 0.36$ mins. In Group B, 44\% of the patients (22 out of 50) could achieve T6 level by 3-4 mins. The mean time taken for sensory analgesia at T6 in Group B was $4.45 \pm 0.03$ mins. The difference in the mean time of onset of sensory analgesia at T6 between Group A and Group B was statistically significant $(\mathrm{p}<0.05)$ (Table 3).

\section{Time of Onset and Duration of Motor Block}

\begin{tabular}{|c|c|c|}
\hline Grade & Criteria & Degree of Block \\
\hline 0 & Free movement in leg and feet & Nil (0\%) \\
\hline 1 & $\begin{array}{c}\text { Just able to flex knee with free } \\
\text { movement of feet }\end{array}$ & Partial (33\%) \\
\hline 2 & $\begin{array}{c}\text { Unable to flex knee with free } \\
\text { movement of feet }\end{array}$ & $\begin{array}{c}\text { Almost complete } \\
(86 \%)\end{array}$ \\
\hline 3 & Unable to move legs of feet & Complete (100\%) \\
\hline \multicolumn{3}{|c|}{ Table 3: Degree of Motor Blockade } \\
\hline
\end{tabular}

The degree of motor block was assessed by Modified Bromage Scale (Table 3). In Group A, 33 patients (66\%) had Grade 3 motor blocks in $2-4$ mins, in 17 patients (34\%) it was achieved in 1-2 mins. The mean time of onset of Grade 3 motor block in Group A was 3.06 \pm 0.9 mins. In Group B, in 32 patients $(64 \%)$ the time of onset of motor block was 6-8 mins whereas in 18 patients (36\%) Grade 3 motor block was achieved only after 8-10 mins. The mean time of onset of Grade 3 motor blocks in Group B was 6.46 \pm 2.48 mins. The difference in mean time of onset of Grade 3 motor blocks was statistically significant $(\mathrm{p}<0.05)$ (Table 4$)$.

In Group A, duration of Grade 3 motor blocks in $62 \%$ (31 patients) of patients was between 90-120 mins and in $38 \%$ of patients (19 patients) it was between $120-180$ mins. The mean duration of Grade 3 motor block in Group A was $120.30 \pm 11.10$ mins. In Group B 94\% (47 patients) of the patients had Grade 3 motor block between 90-120 mins. Only 3 of the patients had motor block beyond 120 minutes. The mean time of duration of Grade 3 motor block in Group B was $102.50 \pm 11.09$ mins. The difference in the mean time of total duration of motor block in Group A and Group B was statistically significant $(\mathrm{p}<0.05)$ (Table 4). 


\section{Regression of the Block}

In Group $\mathrm{A}$, the mean time taken for two segment sensory regression was $92.40 \pm 20.7$ minutes. In Group B, it was $90.6 \pm 20.7$ minutes. The difference in the mean time taken for two segment sensory regression between Group A and Group $B$ is not significant $(\mathrm{p}>0.05)$.

\section{Regression to $\mathbf{L}_{\mathbf{1}}$}

In Group A, 23 patients (46\%) had sensory regression to $\mathrm{L}_{1}$ by $120-180$ mins and the mean time taken for sensory regression to $\mathrm{L}_{1}$ was $144.10 \pm 28.19$ minutes. In Group 2, 22 patients (44\%) had sensory regression to $\mathrm{L}_{1}$ by $90-120$ mins. The mean time taken for sensory regression to $\mathrm{L}_{1}$ was 122.6 \pm 20.5 minutes. The difference in the mean value between group $A$ and group $B$ for sensory regression to $\mathrm{L}_{1}$ was statistically significant $(\mathrm{p}<0.05)$ (Table 4$)$.

\section{Time for Complete Sensory Regression}

In Group A, 31 patients (62\%) showed complete sensory recovery in 160-180 mins. The mean time for complete sensory regression was $169.6 \pm 20.4$ mins. In Group B, 32 patients $(64 \%)$ showed complete sensory recovery in 140 160 mins. The mean time for complete sensory recovery was $150.0 \pm 14.8$ mins. The difference in the mean time for complete sensory recovery between Group A and Group B was statistically significant $(\mathrm{p}<0.05)$ (Table 4$)$.

\begin{tabular}{|c|c|c|c|c|}
\hline $\begin{array}{l}\text { Sl. } \\
\text { No. }\end{array}$ & $\begin{array}{c}\text { Parameter } \\
\text { (In Minutes) }\end{array}$ & $\begin{array}{c}\text { Group } \\
\text { I }\end{array}$ & $\begin{array}{l}\text { Group } \\
\text { II }\end{array}$ & $\begin{array}{c}\text { Statistical } \\
\text { Significance }\end{array}$ \\
\hline 1 & $\begin{array}{c}\text { Mean Time of onset } \\
\text { of sensory analgesia } \\
\text { at } \mathrm{T} 6\end{array}$ & $\begin{array}{l}2.38 \pm \\
0.36\end{array}$ & $4.45 \pm 0.03$ & $\begin{array}{c}\mathrm{p}<0.05, \\
\text { significant }\end{array}$ \\
\hline 2 & $\begin{array}{c}\text { Mean Time for onset } \\
\text { of Grade } 3 \text { motor } \\
\text { block }\end{array}$ & $\begin{array}{c}3.06 \pm \\
0.9\end{array}$ & $6.46 \pm 2.48$ & $\begin{array}{l}\mathrm{p}<0.05, \\
\text { significant }\end{array}$ \\
\hline 3 & $\begin{array}{l}\text { Duration of Grade } 3 \\
\text { motor block }\end{array}$ & $\begin{array}{c}120.30 \pm \\
11.10\end{array}$ & $102.50 \pm 11.09$ & $\begin{array}{l}\mathrm{p}<0.05, \\
\text { significant }\end{array}$ \\
\hline 4 & \multicolumn{4}{|c|}{ Mean time for Regression of the block } \\
\hline & $\begin{array}{l}\text { 1. Two segment } \\
\text { sensory regression }\end{array}$ & \begin{tabular}{|c|}
$92.40 \pm$ \\
20.7
\end{tabular} & $90.6 \pm 20.7$ & $\begin{array}{l}\mathrm{p}>0.05 \text {, Not } \\
\text { significant }\end{array}$ \\
\hline & $\begin{array}{ll}\text { 2. } & \text { Regression to } \\
\mathrm{L}_{1} & \end{array}$ & \begin{tabular}{|c|}
$144.10 \pm$ \\
28.19
\end{tabular} & $122.6 \pm 20.5$ & $\begin{array}{c}\mathrm{p}<0.05, \\
\text { significant }\end{array}$ \\
\hline & $\begin{array}{l}\text { 3. Complete } \\
\text { sensory regression } \\
\text { to } S_{1}\end{array}$ & $\begin{array}{l}169.6 \\
\pm 20.4\end{array}$ & $150.0 \pm 14.8$ & $\begin{array}{c}\quad \mathrm{P}<0.05 \\
\text { significant }\end{array}$ \\
\hline 5 & $\begin{array}{l}\text { Time to first } \\
\text { complaint of pain }\end{array}$ & $\begin{array}{l}170.2 \\
\pm 24.0\end{array}$ & $168.9 \pm 25.5$. & $\begin{array}{c}\mathrm{p}>0.05 \\
\text { Not } \\
\text { significant }\end{array}$ \\
\hline \multicolumn{5}{|c|}{$\begin{array}{l}\text { Table 4: Time of Onset of Sensory and } \\
\text { Motor Block and Regression of Block }\end{array}$} \\
\hline
\end{tabular}

\section{Complications}

Significant complications were not encountered in both groups. Hypotension was noticed in $32 \%$ of patients in Group A and $30 \%$ in Group B. Bradycardia was noticed in $6 \%$ of patients in Group A and 4\% in Group B, but did not need any intervention. Only 3 patients in Group A and 2 in Group B had nausea. None of them had vomiting. Incidence of shivering was also comparable in both the groups with $4 \%$ in Group A and $4 \%$ in Group B. None of the patients had other complications like high spinal, respiratory distress, urinary retention, postdural puncture headache or neurological complications. Neonatal outcome as evidenced by APGAR score was similar in both the groups at 1 minute and 5 minute intervals (Table 5).

\begin{tabular}{|c|c|c|c|c|}
\hline \multirow{2}{*}{ Complications } & \multicolumn{2}{|c|}{ Group I } & \multicolumn{2}{c|}{ Group II } \\
\cline { 2 - 5 } & $\begin{array}{c}\text { No. of } \\
\text { Patients }\end{array}$ & Percentage & $\begin{array}{c}\text { No. of } \\
\text { Patients }\end{array}$ & Percentage \\
\hline Hypotension & 16 & 32 & 15 & 30 \\
\hline Bradycardia & 3 & 6 & 2 & 4 \\
\hline $\begin{array}{c}\text { Nausea and } \\
\text { vomiting }\end{array}$ & 3 & 6 & 2 & 4 \\
\hline Shivering & 12 & 24 & 11 & 22 \\
\hline $\begin{array}{c}\text { Other } \\
\text { complications }\end{array}$ & 0 & 0 & 0 & 0 \\
\hline APGAR Score & \multicolumn{3}{|c|}{ Group I } & Group II \\
\hline 1 minute & \multicolumn{3}{|c|}{$7-9$} & $7-9$ \\
\hline 5 minutes & \multicolumn{3}{|c|}{ Table 5: Complications } \\
\hline \multicolumn{6}{|c|}{}
\end{tabular}

\section{DISCUSSION}

Bupivacaine is the local anaesthetic used routinely for caesarean section, because of its high potency and minimal neurological symptoms. Ropivacaine, an s-enantiomer of bupivacaine is lesser cardiotoxic compared to bupivacaine. ${ }^{1}$ It has shorter duration of motor block with similar sensory block properties compared to bupivacaine-ropivacaine was found to be equipotent to intrathecal Bupivacaine. ${ }^{2,3,4}$ Singh et $\mathrm{al}^{3}$ compared the efficacy of intrathecal $0.75 \%$ isobaric ropivacaine $(24 \mathrm{mg})$ with $0.5 \%$ heavy bupivacaine $(12.5 \mathrm{mg})$ for elective caesarean delivery. Gautier et $\mathrm{al}^{4}$ has found that the lowest dose of ropivacaine that produces anaesthesia comparable with bupivacaine $8 \mathrm{mg}$ in parturients is $12 \mathrm{mg}$. In the present study, we compared the anaesthetic effect of hyperbaric bupivacaine $10 \mathrm{mg}$ to Isobaric Ropivacaine $15 \mathrm{mg}$, because as we did not add opioid for additive effect and our procedure was subarachnoid block without epidural backup. We have compared the onset and duration of sensory and motor block, time of regression of the block, haemodynamics, mean time for first dose of analgesic, complications if any and the neonatal outcome.

\section{Comparison of Sensory Effects}

In our study, the time of onset of sensory analgesia up to T6 level was shorter with Bupivacaine group $(2.38 \pm 0.36)$ as compared to Ropivacaine group (4.45 \pm 0.03$)$, which was statistically significant. Ropivacaine had a slower onset of sensory analgesia compared to Bupivacaine. Similar results were obtained in the study by Malinovsky et $\mathrm{al}^{5}$ where the mean time of onset of analgesia at $\mathrm{T}_{10}$ was 11 min with intrathecal isobaric bupivacaine $10 \mathrm{mg}$ and $13 \mathrm{~min}$ with intrathecal isobaric ropivacaine $15 \mathrm{mg}$.

The time for two segment regression was slightly faster with Ropivacaine $(90.6 \pm 20.7)$ compared to Bupivacaine group (92.40 \pm 20.7$)$, but was not statistically significant. Time of regression of the block to L1 was faster in Ropivacaine group (122.6 \pm 20.5$)$ than with Bupivacaine group $(144.10 \pm 28.19)$. The difference in the mean value between Group A and Group B for sensory regression to $\mathrm{L}_{1}$ was statistically significant $(\mathrm{p}<0.05)$. Our results correlated with those of Gautier P, Malinovsky and Chan-Jong Chung et al, where a faster time of regression of block to L1 was noted. $4,5,6$ 
Likewise, the mean time for complete regression of the block to S1 was slightly faster in Ropivacaine group $(150.0 \pm 14.8)$ as compared to Bupivacaine group (169.6 \pm 20.4$)$. The difference in the mean time was statistically significant with a $\mathrm{p}$ value of $<0.05$. Our findings were similar to the study by Chung et al, where the time of regression of block to S1 was longer (188.56 $\pm 28.2 \mathrm{~min})$ in Bupivacaine group when compared to Ropivacaine group $(162.56 \pm 20.2 \mathrm{~min})^{6}$

\section{Comparison of Motor Effects}

In our study, the mean time for onset of Grade 3 motor block was $3.06 \pm 0.9$ minutes in Bupivacaine group as against $6.46 \pm 2.48$ minutes in Ropivacaine group. The difference between the two groups was statistically significant $(\mathrm{p}<0.05)$. In our study, Ropivacaine produced motor block much slower than Bupivacaine. We also observed a shorter duration of motor blockade with ropivacaine compared to bupivacaine. The mean duration of motor blockade was $102.50 \pm 11.09 \mathrm{~min}$ with ropivacaine and $120.30 \pm 11.10$ min with bupivacaine. Our findings were in affirmation with the study of Chan Jong Chungar et al, where motor blockade with hyperbaric ropivacaine $18 \mathrm{mg}$ was $113.7 \mathrm{~min}$ compared to $158.7 \mathrm{~min}$ with hyperbaric bupivacaine $12 \mathrm{mg} .{ }^{6}$ Boztug et al observed complete motor blockade in $88 \%$ of patients receiving ropivacaine and $100 \%$ patients receiving bupivacaine when administered for knee arthroscopy. ${ }^{7}$ In our study both the groups developed complete motor block, albeit a slower onset in ropivacaine group.

On the whole, in our study the onset of motor block was slower in Ropivacaine group and was of shorter duration than Bupivacaine group, whereas sensory block was comparable in both the groups. Similar study by Kallio et al comparing intrathecal bupivacaine and ropivacaine found that the duration of sensory block of ropivacaine was twothirds and the duration of motor block was half when compared with bupivacaine. ${ }^{8}$

Mean duration for request of analgesia was comparable in both groups in our study. There was no statistical difference between APGAR scores in both the groups. There are significantly fewer side-effects such as hypotension, nausea, shivering and bradycardia in both the ropivacaine and bupivacaine group. The results of our study are similar to various studies in the literature.9,10,11,12,13

\section{CONCLUSION}

Intrathecal Isobaric Ropivacaine $15 \mathrm{mg}$ provides effective spinal anaesthesia for caesarean delivery. It has slower onset, shorter motor block, early sensory regression and similar postoperative analgesia and APGAR scores as compared to 10 mg of $0.5 \%$ hyperbaric bupivacaine. The shorter duration of motor block can facilitate early ambulation and makes ropivacaine a good alternative for elective caesarean deliveries.

\section{REFERENCES}

1. Gaurav Kuthiala, Geeta Chaudhary. Ropivacaine: a review of its pharmacology and clinical use. Indian J Anaesth 2011;55(2):104-10.

2. De Kock M, Gautier P, Fanard L, et al. Intrathecal ropivacaine and clonidine for ambulatory knee arthroscopy: a dose response study. Anaesthesiology 2001;94(4):574-8.

3. Singh S, Singh VP, Jain M, et al. Intrathecal $0.75 \%$ isobaric ropivacaine versus $0.5 \%$ heavy bupivacaine for elective caesarean section delivery: A randomized controlled trial. J Pak Med Stud 2012;2(2):75-80.

4. Gautier P, De Kock M, Huberty L, et al. Comparison of the effects of intrathecal ropivacaine, levobupivacaine, and bupivacaine for caesarean section. $\mathrm{Br} \mathrm{J}$ Anaesth 2003;91(5):684-9.

5. Malinovsky JM, Charles F, Kick O, et al. Intrathecal anaesthesia: ropivacaine versus bupivacaine. Anaesth Analg 2000;91(6):1457-60.

6. Chan-Jong Chung, So-Ron Choi, Kwang-Hwan Yeo, et al. Hyperbaric spinal ropivacaine for caesarean delivery: a comparison to hyperbaric bupivacaine. Anaesthesia and analgesia 2001;93(1):157-61.

7. Neval Boztug, Zekiye Bigat, Bilge Karsli, et al. Comparison of ropivacaine and bupivacaine for intrathecal anaesthesia during outpatient arthroscopic surgery. Journal of Clinical Anaesthesia 2006;18(7):521-5.

8. Kallio H, Snall EV, Kero MP, et al. A comparison of intrathecal plain solutions containing ropivacaine 20 or $15 \mathrm{mg}$ versus bupivacaine $10 \mathrm{mg}$. Anaesth Analg 2004;99(3):713-7.

9. Ogun CO, Kirgiz EN, Duman A, et al. Comparison of intrathecal isobaric bupivacaine- morphine and ropivacaine- morphine for caesarean delivery. $\mathrm{Br} \mathrm{J}$ Anaesth 2003;90(5):659-64.

10. Dhalwani, Nafeesa. Ropivacaine versus bupivacaine for spinal anaesthesia in elective caesarean deliveries. Journal of Pioneering Medical Sciences 2012;2(2):73-4.

11. Nuray CE, Berrin G. A comparison of the effects of intrathecal ropivacaine and bupivacaine during caesarean section. Turk J Med Sci 2011;41(2):219-26.

12. Tao Xu, Jia Wang, Geng Wang, et al. Relative potency ratio between hyperbaric and isobaric solutions of ropivacaine in subarachnoid block for knee arthroscopy. Int J Clin Exp Med 2015;8(6):9603-6.

13. Tadu LC, Usha Suwalka, Ladhu Lakra, et al. Intrathecal $0.75 \%$ isobaric ropivacaine versus $0.5 \%$ heavy bupivacaine for elective caesarean delivery: a randomized comparative study in hundred patients. NJIRM 2014;5(6):44-8. 